\title{
RA?EGA
}

O ESPACYO GEOGRÁFICO EM ANÁLISE

\section{AVALIAÇÃO DA GESTÃO DE RISCO DE ESCORREGAMENTOS NO MACICO DO MORRO DA CRUZ, FLORIANÓPOLIS, SC}

\section{EVALUATION OF LANDSLIDE RISK MANAGEMENT IN MACIÇO DO MORRO DA CRUZ, FLORIANÓPOLIS,SC}

Silvia Midori Saito

Pesquisadora

Centro Nacional de Monitoramento e Alertas de Desastres Naturais - CEMADEN

Cachoeira Paulista, SP, Brasil e-mail: silvia.saito@cemaden.gov.br

Joel Robert Georges Marcel Pellerin Professor do Programa de Pós-Graduação em Geografia Universidade Federal de Santa Catarina - UFSC

Florianópolis, SC, Brasil e-mail:pellerin@cfh.ufsc.br

Recebido em: 23/10/2012.

Aceito em: 20/11/2013.

\section{Resumo}

A gestão de risco no Brasil, por muito tempo, esteve relacionada apenas ao atendimento de emergências. Esse processo, entretanto, envolve ações em identificação, prevenção e redução dos riscos. O presente artigo analisou as práticas na gestão de risco a escorregamentos no Maciço do Morro da Cruz, em Florianópolis, Santa Catarina. Especial atenção foi dada aos dezesseis assentamentos precários existentes na área de estudo expostos ao risco de deslizamentos em diferentes graus. O estudo revelou que muitas ações isoladas foram efetuadas pelos diversos atores envolvidos, mas ainda nada se faz de maneira sistêmica, que contribua para o desenvolvimento municipal.

Palavras-Chave: gestão de risco, escorregamento, assentamentos precários.

\section{Abstract}

Along years, risk management in Brazil has been only related to emergencies. However, this process enabled actions involving identification, prevention and 
reduction of risks. This paper analyzed the practices in landslides risk management in Maciço do Morro da Cruz, Florianopolis, Santa Catarina. Sixteen precarious settlements had special attention in this analysis due to the landslides risk areas in different degrees. The study showed that isolated actions are performed by the many actors involved, but none is done in a systematic way that contributes to municipal development.

Keywords: risk management, landslide, precarious settlements.

\section{INTRODUÇÃO}

No Brasil, após a ocorrência de um desastre natural de alta intensidade, em meio ao resgate de vítimas, a distribuição de donativos e a contabilização dos mortos, iniciam-se os questionamentos: quem foram os culpados? Era possível prever que ocorreria? A área será novamente ocupada? Entre questões que envolvem o passado e o futuro, o consenso é de que pouco se fez, e se faz, para evitar tamanhas tragédias que envolvem dramas familiares, impactos à economia local e regional, desequilíbrios em contas públicas, problemas de saúde, entre outras consequências.

Um avanço significativo em termos de concepção de gestão de risco no país foi a promulgação da Lei 12.608/2012, que instituiu a Política Nacional de Proteção e Defesa Civil - PNPDEC. Essa lei possui caráter inédito no Brasil, uma vez que atribuiu a União, estado e municípios, responsabilidades principalmente em ações de defesa civil e planejamento urbano.

Diante desse contexto, o objetivo do presente artigo foi analisar as principais práticas em gestão de risco de escorregamentos no Maciço do Morro da Cruz (MMC), Florianópolis, Santa Catarina. Especial atenção foi dada aos dezesseis assentamentos precários presentes no MMC. Estes são mostrados na Figura 1 e compreendem: Alto da Caieira, Angelo Laporta, José Boiteux, Laudelina Cruz Lemos, Monte Serrat, Morro da Mariquinha, Morro da Penitenciária, Morro da Queimada, Morro do 25, Morro do Céu, Morro do Horácio, Morro do Mocotó, Morro do Tico Tico, Santa Clara, Serrinha, e Vila Santa Vitória. A população total no MMC em 2004, segundo levantamento realizado pela Prefeitura Municipal de Florianópolis (PMF), era de aproximadamente 25 mil pessoas. 
De acordo com o Plano Municipal de Redução de Risco (PMRR, 2006), estimava-se que havia 59 áreas de riscos de deslizamentos no MMC, das quais 10 de eram consideradas como risco baixo, 21 de risco médio, 20 de risco alto e 8 de risco muito alto. Dentre tais áreas, muitas receberam melhorias de infraestrutura para a redução do risco, através de recursos do PAC (Plano de Aceleração do Crescimento), do governo federal.

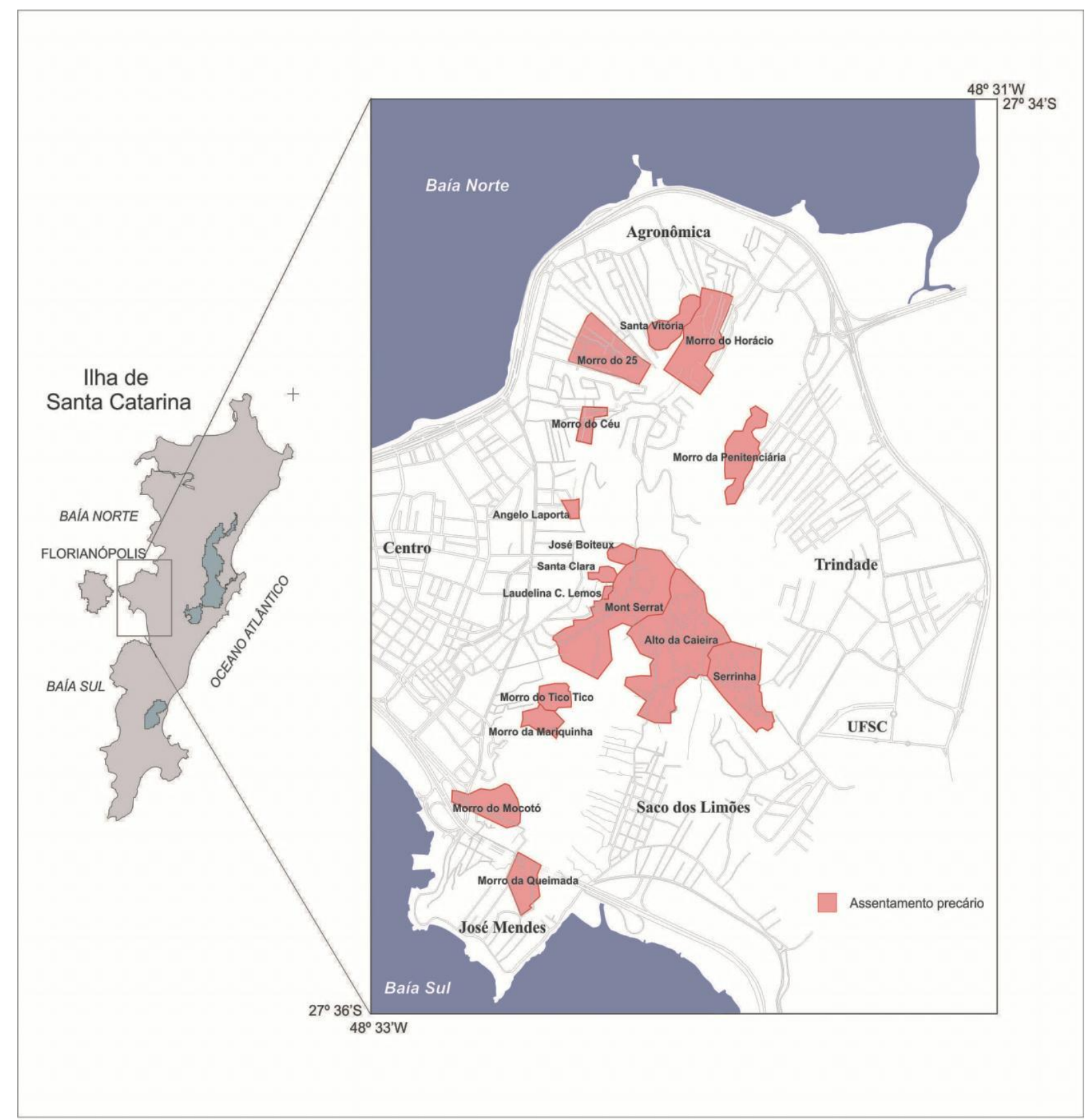

Figura 1: Localização dos assentamentos precários do Maciço do Morro da Cruz. 
Ao partir para análise sobre as práticas em gestão de risco, tomando o $\mathrm{MMC}$ como estudo de caso, espera-se fornecer algumas reflexões, sobre as boas práticas bem como os desafios a serem vencidos, para que se possa melhor entender 0 papel dos diversos agentes envolvidos, como poder público e comunidade.

\section{SOBRE GESTÃO DE RISCO (GR)}

A palavra gestão significa "ato de gerir"; gerir por sua vez, vem de gerere de origem latina que quer dizer "ter gerência sobre, administrar" (HOUAISS, 2003). Dessa maneira, pressupõe que haja um conhecimento amplo de determinado processo, que pode ser na área da saúde, engenharia, industrial, etc. Dada sua abrangência, no ano de 2009 a Associação Brasileira de Normas Técnicas (ABNT) lançou a ISO 31000, fornecendo princípios e diretrizes genéricas para a gestão de riscos.

$\mathrm{Na}$ área de desastres naturais, a gestão de risco almeja reduzir as consequências negativas ou perdas potenciais. Costuma-se dizer que só se faz gestão de uma ameaça conhecida, ou seja, não se administra algo que nunca ocorreu.

A discussão teórica a respeito desse conceito foi realizada mais amplamente por instituições internacionais que atuam em risco de desastres naturais, tais como Centro de Coordinación para la Prevención de los Desastres Naturales en América Central (Cepredenac), Estrategia Internacional para Reducción de Desastres (EIRD), Grupo Internacional Recursos del Sur da United States Agency for International Development (USAID). Por essa razão, as principais diretrizes discutidas em tais obras foram adotadas no presente artigo.

Embora com algumas variações entre as instituições, as etapas que constituem a gestão de risco podem ser definidas como avaliação de riscos, redução de riscos, manejo de eventos adversos e recuperação. As definições do Cepredenac e USAID destacam que todo o processo de gestão de risco almeja como resultado, o desenvolvimento, pois "risco e desastre são então a antítese do desenvolvimento (...). O risco é sinônimo de insegurança e o desastre um reflexo da insustentabilidade" (Cepredenac, 2003, p.12, tradução nossa). 
A avaliação de riscos necessita invariavelmente ser elaborada anterior às demais fases. Nessa etapa, identificam-se os fenômenos de origem natural ou mista, que quando manifestados representam ameaça a uma sociedade, gerando prejuízos. Características como condicionantes de ocorrência, área de abrangência e tempo de recorrência, são aspectos fundamentais para essa identificação. Os conhecimentos são distintos por fenômeno, ou seja, os aspectos pertinentes às inundações não se aplicam aos escorregamentos. Ainda é importante avaliar a possibilidade de processos secundários, tanto naturais como antrópicos.

Constata-se, assim, o importante papel desempenhado pelos diferentes campos científicos, como geologia, geografia, meteorologia, engenharias, sociologia, entre outros, e suas respectivas pesquisas. A partir desses conhecimentos, pode-se, por exemplo, gerar modelos que simulem a ocorrência de processos, a que podem ser úteis tanto em medidas estruturais como não estruturais. Kobiyama et al. (2004) exemplificam que para o caso de inundações, os modelos podem auxiliar tanto para a construção de barragens como para o zoneamento ambiental, considerando as ameaças existentes.

O outro aspecto da avaliação de risco é a determinação das vulnerabilidades existentes, tanto da população como da infraestrutura. Mesmo conscientes de que o resultado das vulnerabilidades atuais decorre de processos históricos, na gestão deve-se trabalhar com cenários concretos. Para tanto, faz-se necessário um monitoramento constante, tendo em vista o dinamismo que envolve atualmente 0 uso e a ocupação do solo.

Após a avaliação de riscos, pode-se desenvolver as demais etapas da gestão, que serão abordadas a seguir em ordem que representa apenas como recurso didático, mas não de importância.

A redução de riscos constitui-se outra fase no processo de gestão. $O$ Cepredenac assume o conceito como a execução de medidas de intervenção dirigidas a reduzir ou diminuir o risco existente. Essa etapa provavelmente é a mais custosa entre as demais, pois implica em remoção de ocupações e construção de obras de infraestrutura, além de envolvimento de equipes multidisciplinares. Por exemplo, retirar uma comunidade de área de risco exige muito além de alocá-la em 
um terreno seguro, necessita, ainda, de um acompanhamento para a adaptação social, garantias de integração ao convívio do novo assentamento, entre outras.

Diante do cenário atual de ocupação no Brasil é factível trabalhar com a ideia de risco aceitável. A EIRD (2004, p. 7, tradução nossa) o define como "O nível de perda que uma sociedade ou comunidade considera aceitável dado a existência das condições social, econômica, política, técnica e ambientais". Segue exatamente a perspectiva de conviver com o risco e por isso, ações podem ser tomadas nesse sentido.

Também fazendo adoção do conceito de risco aceitável, a prevenção de riscos é outro estágio da GR, e provavelmente constitui-se como a mais importante. Conceitualmente, existe uma nuance utópica ao dispor que se deve prevenir novos riscos e impedir que outros apareçam. Por isso, a necessidade de se lidar com o risco aceitável (Cepredenac, 2003). As medidas não estruturais devem receber especial atenção dada sua eficácia, em especial aquelas voltadas para a formação dos indivíduos, seja por meio formal ou não-formal. Nesse sentido, pode-se preparar as populações moradoras em áreas de risco a interpretar sinais de instabilidade na encosta, ou mesmo compreender o significado de um alerta emitido pela defesa civil.

A gestão de risco ainda deve prever o manejo de eventos adversos, ou seja, a coordenação das ações durante o desastre. Esse é justamente o momento em que se prevê como enfrentar o impacto dos eventos e seus efeitos, ao mesmo tempo em que se realizam as atividades de resposta imediata como evacuação, resgate dos afetados e a redução das perdas materiais. De modo geral, já se percebe avanços significativos como a implementação de planos, programas e protocolos na América Latina (PRIETO, 2007).

A reconstrução é a fase do pós-desastre, quando se trabalha em direção ao restabelecimento das condições normais da comunidade afetada. Em curto prazo, tem-se a reabilitação, quando ocorre a recuperação dos serviços básicos, como água e luz. A médio-longo prazo, é feita a reconstrução, caracterizado pelo processo de reparação dos danos físicos, sociais e econômicos ao nível de desenvolvimento superior ao existente pré-desastre. É o momento de reavaliar se práticas de ocupação serão mantidas ou não e considerar se o risco passou de aceitável para intolerável. 
Assim, a partir do entendimento acima exposto, buscou-se identificar qual o contexto das práticas e desafios diante da realidade do MMC para a gestão de riscos. Por se tratar de um modelo conceitual que entende a gestão como um processo social em um cenário, cada etapa foi analisada enfocando a ação de cada agente produtor dessa realidade.

\section{ANÁLISE DE RISCO}

É indiscutível que o risco é cambiante e é influenciado, sobretudo, por uma de suas componentes, a vulnerabilidade. Isto quer dizer que é possível reduzir a exposição da população e melhorar sua capacidade de resposta, pois na maior parte das situações, pouco se pode fazer para que o fenômeno perigoso não ocorra, a exemplo de tempestades severas. Por isso a importância de se conhecer a ameaça a que está submetida uma determinada comunidade.

O levantamento sistemático das ocorrências registradas no $M M C$, que contribui para a identificação das ameaças, ainda é deficiente e dessa maneira acaba por prejudicar o melhor conhecimento sobre a frequência e intensidade do fenômeno. A iniciativa de organização de registros históricos ou de intervenções estruturais no MMC, mas não exatamente para esse fim, foi realizada por Rego Neto (1988) e Saito (2004), a partir de dados da Defesa Civil, Corpo de Bombeiros e notícias de jornais.

A atribuição de organizar o banco de dados, que deveria ser executada por aqueles agentes que atuam no atendimento em situações críticas e no planejamento, como Defesa Civil e/ou Prefeitura, é realizada a cada nova chefia ou gestão municipal, tendo em vista que são atribuídas a cargos de confiança. A ruptura de organização dos dados a cada nova gestão poderia ser evitada caso a responsabilidade fosse delegada a cargos permanentes. Nesse sentido, cita-se o caso do quadro de profissionais do Departamento Estadual de Defesa Civil/SC, descrito por Negredo (2010): por contar com efetivo de militares estaduais, que ganham gratificação por estar nessa função, os cargos acabam associados ao grupo político dominante. Assim, a cada troca de governo, altera-se o quadro de profissionais. 
Em Florianópolis, a situação é bastante semelhante já que a Defesa Civil está vinculada à Guarda Municipal da Secretaria Municipal de Segurança e Defesa do Cidadão. Nesse caso, os cargos também estão associados à gestão municipal e por consequência, a uma questão política. Depara-se, então, ao final de quatro anos (ou até menos, em função da demanda política) após a formação de profissionais preparados em atuar em eventos adversos, com um quadro completamente novo de funcionários. Tal ingerência de recursos humanos ocorre na maior parte dos municípios brasileiros, com raras exceções, o que evidencia a falta de conhecimento dos gestores sobre o importante papel da Defesa Civil no município.

Sob o ponto de vista da análise das condicionantes dos escorregamentos no MMC, foram realizados trabalhos com esse propósito, a exemplo de Rego Neto (1988), Afonso (1992), Tomazzoli e Pellerin (2002), Saito (2004) e o PMRR (2006). Ainda que cada trabalho tenha sido desenvolvido empregando diferentes métodos e escalas, todos colaboraram para melhor conhecer a dinâmica do ambiente e ainda as características dos escorregamentos, que podem causar impactos negativos às comunidades.

Além da identificação das ameaças é necessário conhecer as principais vulnerabilidades existentes. Quem e o que é vulnerável diante da ocorrência de eventos adversos são imprescindíveis para a gestão de risco. Observa-se que para o MMC, os primeiros estudos foram realizados pelo IPUF (1993) que realizou um levantamento sobre as comunidades carentes de Florianópolis. Posteriormente, em 2002, foi realizado um perfil socioeconômico dos moradores do Morro do Mocotó para o projeto Bom Abrigo e em 2006, o PMRR (2006) também realizou um levantamento socioeconômico, por amostragem, dos moradores dos assentamentos precários de Florianópolis.

Ainda é fundamental identificar as estruturas mais vulneráveis, tanto públicas como privadas. Estabelecimentos de saúde e de ensino são considerados como construções que devem estar localizados em locais seguros (EIRD, 2004). Tal é a importância, que essa foi eleita uma das prioridades no Marco de Ação de Hyogo. Isso porque as crianças são mais vulneráveis diante de uma situação de desastre já que possuem baixa capacidade de resposta. Soma-se, ainda, ao alto custo de reconstrução e o tempo despendido, que certamente acarreta em atraso das aulas. 
$\mathrm{E}$, também, ao uso constante de escolas como abrigos temporários, o que reforça a necessidade de garantir a segurança de todos que nelas estão abrigados.

Os estabelecimentos municipais de saúde que atendem a população moradora do MMC estão localizados no Mont Serrat, Agronômica, Prainha e Trindade. Salvo o primeiro, os demais estão situados nas principais avenidas dos respectivos bairros. O Centro de Saúde do Mont Serrat está localizado adjacente à comunidade. O Hospital Infantil Joana de Gusmão, vinculado à Secretaria Estadual de Saúde, localizado no bairro Agronômica, em janeiro de 2011 foi afetado por alagamentos que comprometeram setor farmacêutico e o banco de sangue, o que demonstrou a sua vulnerabilidade.

A construção de cenários, a partir do conhecimento detalhado das ameaças e das vulnerabilidades, permite o manejo do desastre pelos diferentes agentes em situações emergenciais, bem como subsidiar diretrizes para ações preventivas de danos materiais e humanos. Logo, é focada tanto às estruturas físicas e humanas e às ações emergenciais e de planejamento. Segundo Cepredenac (2003), as acepções mais recentes consideram o entendimento dos processos e atores sociais que contribuem para configurar o cenário de risco. Assim, tenta superar a noção de que os prejuízos são causados sem causalidade.

\section{REDUÇÃO DE RISCO}

Após a identificação das ameaças que podem afetar a população, sistemas físicos e humanos vulneráveis, parte-se para a fase de redução de risco, caracterizada tanto por medidas estruturais como não estruturais que visem eliminar ou reduzir o risco existente. Historicamente, a PMF através de suas secretarias e órgãos, elaborou diversas ações em caráter emergencial para o desmonte e fixação de blocos, como no Morro do Mocotó e Morro do Horácio em 1988 e 1990, respectivamente; construção de muros de contenção, a exemplo do Saco dos Limões em 1991; execução de drenos no Mont Serrat em 1986; entre outras (RAIMUNDO, 1998).

Como exemplo de medidas não estruturais, a Fundação Municipal do Meio Ambiente (Floram) realizou a partir do ano 2000, projetos como Pomar Floripa e Recomposição das Áreas Degradadas do Morro da Cruz com vistas à recuperação 
vegetal com plantio de espécies nativas. Posteriormente, em 2005, foi aprovada a lei complementar ํo 207/05 ao Plano Diretor, a qual regulamentava a criação das Zonas de Especial Interesse Social no MMC. Esse foi o primeiro passo para a regulamentação dos chamados "assentamentos subnormais".

As primeiras significativas intervenções estruturais foram realizadas a partir da chamada "Operação Tapete Preto", cuja proposta era a pavimentação de ruas em diversas áreas de Florianópolis, Em 2006, foi elaborado o Plano Municipal de Redução de Risco, o qual definia as áreas de risco de escorregamentos no MMC e em demais encostas urbanizadas de Florianópolis. A partir de 2008, com o PAC, as obras ocorreram de modo a prover melhorias como muros de contenção e pavimentação. Assim, ações efetivas estavam se consolidando, mesmo que de maneira fragmentada, para a gestão de risco no MMC. Diante desse novo cenário, acenava-se para mudanças do grau de risco a escorregamentos no MMC.

Exemplo da alteração do grau do risco é verificado ao acompanhar a evolução da paisagem na comunidade da Serrinha. Conforme se observa na Figura 2. No ano de 2004 , as moradias eram predominantemente de madeira e com um pavimento, algumas com baixo padrão construtivo. As tubulações de água estavam expostas em meio à ocupação, passíveis de vazamentos e contaminação. Ainda não havia ordenamento das águas superficiais. Embora de menor altura, taludes de corte eram elaborados para a construção das moradias, bem como taludes de aterro. Em 2010, chama a atenção o fato de que havia poucos espaços vazios para a construção de novas residências. A Serrinha também recebeu obras de infraestrutura custeadas pelo PAC, sendo possível observar a melhoria de acesso e a regularização dos serviços de água, esgoto e luz, fornecidos a partir de 2009.

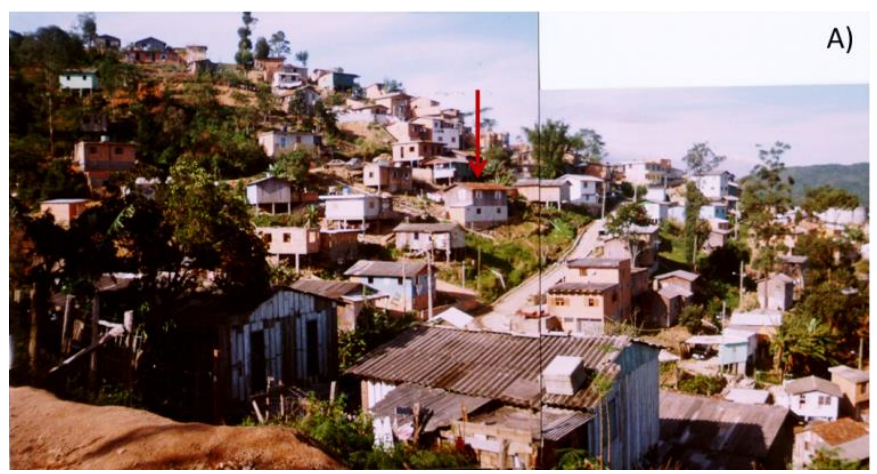

Figura 2: ocupação na Serrinha, em 2004

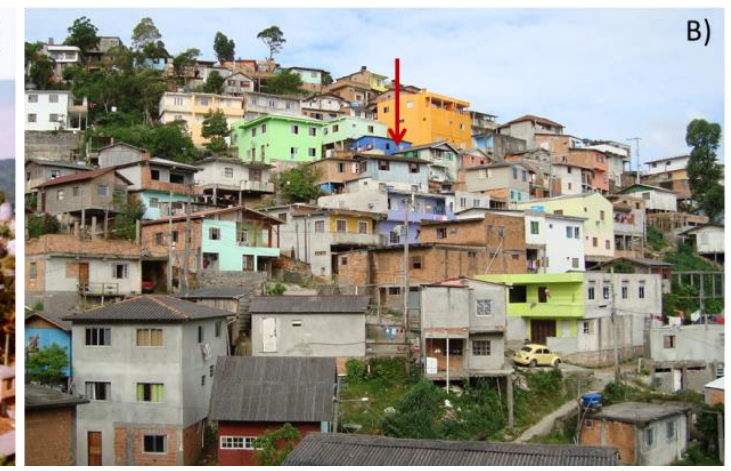

(A) e 2010 (B). Fotos: dos autores. 
A situação na Serrinha evidencia, notadamente, o adensamento das moradias. Depois, a melhoria da qualidade das casas: de madeira para alvenaria e a troca de telha de fibrocimento por cerâmicas. Destaca-se, ainda, a verticalização das moradias, algumas delas com até três pavimentos. Esse aumento da área construída leva a acreditar que seja uma própria demanda familiar, com aumento de membros ou a (sub) locação do imóvel, em função da proximidade a UFSC e do centro da cidade. Outro aspecto que chama atenção é o maior cuidado com a moradia, evidenciado através da pintura com cores fortes, indicando um desejo de diferenciá-la dentre as demais. O maior apego e investimento nas moradias podem ser relacionados com a perspectiva de posse do imóvel, fato que não ocorria anteriormente.

Essas novas condições modificaram o grau do risco de escorregamento: do ponto de vista da exposição física, houve redução com a melhoria das construções, entretanto, o adensamento concorreu para sua elevação. O maior número de moradores exige uma maior demanda de água para consumo bem como da rede de esgoto. Em caso de vazamentos, provocados tanto pela rede formal como pelas ligações informais, aumenta a possibilidade de ocorrer possíveis instabilidades no terreno. Em caso de acidente, o número de vítimas também será maior; já em situação de evacuação da área, seja por escorregamento ou até por incêndio, também amplia a necessidade de melhores escadarias e vias de circulação.

Ainda no âmbito das políticas públicas, outra ferramenta de planejamento urbano é o Plano Diretor, eficiente para a adoção de medidas preventivas, mesmo que não totalmente isento de interesses e forças dos agentes atuantes na configuração do desenho da cidade. Através do zoneamento do uso do solo é possível restringir a ocupação em áreas suscetíveis, como planícies de inundação ou encostas íngremes.

Como anteriormente citado, a incorporação ao Plano Diretor de Florianópolis dos assentamentos precários do MMC como ZEIS criou um mecanismo legal de prover tais áreas com serviços e infraestrutura básicas. Ainda colabora ao criar uma legislação urbanística específica nessas áreas impedindo, por exemplo, o adensamento de moradias. Mas essa iniciativa configura apenas o primeiro passo de inserção das comunidades à cidade formal. Deve-se prever outras estratégias 
que garantam a permanência dos moradores e que posteriormente tais áreas não se constituam alvos de especulação imobiliária, dada sua localização central.

A reurbanização de ocupações informais consolidadas tem como resultado não apenas a melhoria do ambiente construído - a exemplo de inúmeras experiências positivas em Recife, Porto Alegre, São Paulo e Rio de Janeiro, mas ainda das relações entre moradores e deles com sua comunidade. Por isso, a importância da participação popular na elaboração do Plano Diretor.

Por fim, o poder público pode atuar na fiscalização de ocupações, coibindo novas construções em áreas já ocupadas, prática conhecida como "congelamento de áreas de risco". A PMF, através da Secretaria de Meio Ambiente e Desenvolvimento Urbano, em julho de 2010 lançou campanha que incentivava a população a denunciar construções em áreas de risco.

Ainda no rol de medidas não estruturais de redução, o alerta de risco auxilia na mitigação de prejuízos e perdas de vidas. É a identificação da possibilidade de um fenômeno perigoso afetar uma área ocupada e comunicada à população através de órgão competente. O alerta pode ser dado em decorrência de um evento extremo de curta duração e que exija rápida resposta, como as tempestades, como também para fenômenos de longa duração, como as secas.

É notável a melhoria da rede observacional no país, mas na medida em que se investe em tecnologia para a melhora da previsão do tempo, o mesmo não se faz em educação e capacitação e tampouco se adota uma cultura de prevenção. Algumas iniciativas foram identificadas: em 2008, o Departamento Estadual de Defesa Civil/SC, juntamente com a UFSC e o governo do estado, promoveram a formação de lideranças comunitárias do MMC em um projeto denominado como Percepção de Risco: a descoberta de um novo olhar. Esse é um caminho concreto que mostra que a educação deve ser trabalhada em todos os níveis, formal como não formal, e para todas as idades. Além de evidenciar que a responsabilidade perante os desastres não é atribuída apenas ao poder público, mas toda a sociedade envolvida.

\section{PREVENÇÃO DE RISCO}


A definição de prevenção de riscos requer trabalhar com medidas ante as ameaças e vulnerabilidades prováveis, ou seja, são disposições elaboradas para impedir que novos riscos sejam criados. Nesse sentido, o Cepredenac (2003) avalia que levada a cabo, essa noção acaba por ganhar uma conotação utópica e por essa razão, a necessidade de trabalhar na perspectiva do risco aceitável.

Pode-se afirmar, sem a possibilidade de incorrer em erro, que diante da realidade brasileira - e de outros muitos países, é inexistente a prática de ações preventivas, pois as medidas até então executadas foram para reduzir o risco, ou seja, de um cenário já consolidado que apresenta condições prováveis de provocar danos. São ações no âmbito da gestão corretiva, pois reduzir o risco a zero, implica em, por exemplo, remover completamente a ocupação de uma área suscetível, o que resultaria em elevado investimento financeiro e em alto impacto social.

Conviver com o risco tem sido a alternativa adotada em muitos assentamentos no país. Mas não é feito de maneira adequada, ou seja, em que a população vulnerável conheça 0 momento em que o aceitável passa a ser intolerável. Assume-se que os benefícios em se ocupar uma determinada área sejam maiores do que os agravos (sociais, ambientais e econômicos) em caso de um desastre. Para tanto, é necessária a consciência das ameaças existentes e o gerenciamento da crise, em que a população saiba exatamente o que fazer durante um evento adverso, como procurar os abrigos e as rotas de fuga - ações previstas em um plano de contingência.

Uma sociedade preparada significa uma sociedade resiliente. Além disso, é através do zoneamento em que se definem áreas suscetíveis a processos perigosos e consequentemente, coíbe-se a ocupação das mesmas. Isso demonstra a importância de analisar o risco sob a perspectiva quantitativa ao indicar índices críticos de precipitação, mapear áreas suscetíveis, construir obras de contenção, etc. Contudo, expõe que abordagens qualitativas também são imprescindíveis para o enfrentamento dos desastres, associando a dinâmica dos processos sociais à realidade.

\section{DISCUSSÃO DOS RESULTADOS}


Á guisa de compreensão, não existe ainda no MMC um eixo norteador para a gestão de risco entendido como um processo social que tem por fim 0 desenvolvimento. Ações isoladas e paralelas são efetuadas, em especial desde 2005, pelos diversos agentes em prol da redução do risco. A experiência existente até então era aquela que fazia o gerenciamento da crise. Destaca-se a participação de todos envolvidos nas três etapas da gestão de risco e como se pode observar, foi caracterizada pela particularidade de cada caso sob análise, demonstrando a necessidade do conhecimento dos processos locais de organização social, intervenção pública, entre outros.

$\mathrm{Na}$ primeira fase constituída pela avaliação de riscos, destacaram-se fundamentalmente os trabalhos científicos executados nas instituições de ensino superior, que contribuíram para o melhor conhecimento das ameaças. Sobre as vulnerabilidades, os estudos ainda são muito incipientes e é necessária uma maior gama de estudos. A UFSC, em particular, colaborou ainda para a aproximação do diálogo entre entidades comunitárias e meio acadêmico.

Para a redução do risco, as obras de contenção e de infraestrutura executadas pela PMF reduziram a exposição física dos moradores do MMC. Mas em paralelo, medidas não estruturais auxiliaram para aumentar a capacidade de resposta da população por meio de cursos de capacitação. E, ainda, através do planejamento e planos de habitação de interesse social.

O reconhecimento como ZEIS, só foi permitido através de uma mudança de concepção sobre regularização fundiária, dada pela lei federal 10.257/01, o Estatuto da Cidade. Posteriormente, os investimentos do PAC, outra medida na esfera federal, auxiliaram na promoção de infraestrutura básica ao MMC.

Logo, tais aspectos devem ser considerados na gestão de risco e leva a destacar a necessidade de constante atualização dos cenários, em função de como já citado anteriormente, da dinâmica do risco. Outros desafios ainda necessitam ser superados, a exemplo de conhecimento aprofundado das vulnerabilidades existentes no MMC. A educação em todos os níveis também deve ser tomada como prioridade, sobretudo porque contribui para sociedades mais preparadas e conscientes do risco. Outra necessidade é a de fortalecer as relações entre os moradores para aumentar a capacidade de resposta. Esse fortalecimento gera 
consequentemente a melhor comunicação, o que também será benéfico para a eficiência dos alertas.

A intervenção estrutural embora seja custosa é imprescindível para a redução do risco em diversas comunidades do MMC. Muitas moradias apresentam baixíssimo padrão construtivo, o que pode provocar acidentes independentes da ocorrência de chuvas intensas. A melhoria da acessibilidade além de possibilitar fuga em caso de evacuação colabora para a qualidade de vida dos moradores.

Esse é o contexto para que se possa criar uma cultura de prevenção de risco, em sua definição propriamente dita. Se tais desafios forem vencidos, não se fará mais o manejo da crise, mas sim a gestão prospectiva de uma ameaça que não se manifestou ainda.

\section{CONSIDERAÇÕES FINAIS}

Partindo finalmente para a análise sobre a gestão de risco, constataram-se inúmeras ações isoladas que foram realizadas para a avaliação e a redução do risco no MMC. Sob a perspectiva do risco aceitável, foram desenvolvidas obras estruturais, as quais reduziram o grau de exposição física da população. Por outro lado, deve-se fortalecer atividades que desenvolvam a percepção dos moradores dos riscos a que estão submetidos. O principal resultado é uma comunidade consciente e preparada para dar rápida resposta mediante um desastre. Ainda se faz necessário o desenvolvimento de protocolos de resposta aos desastres, a exemplo dos planos de contingência.

Mas o agente decisivo para a gestão de riscos é o poder público. Por muitos anos, milhares de moradores dos assentamentos do Maciço foram privados de serviços como água e luz, por decisão da Prefeitura. Apenas com a mudança da gestão municipal e influenciada também pelo cenário federal, é que se começa de fato, a estender políticas públicas também aos assentamentos precários. Além disso, a partir de recursos federais do PAC, juntamente com auxilio estadual, é que se pôde promover a melhoria da infraestrutura dos assentamentos do MMC.

Contudo, não se deve atribuir exclusivamente a responsabilidade da gestão ao poder público. A sociedade civil também tem participação decisiva nesse processo: a comunidade científica tem relevante papel ao contribuir com 0 melhor 
conhecimento sobre as ameaças e as vulnerabilidades; as organizações sociais promovem a maior coesão entre os moradores; e a população deve evitar práticas de ocupação que as exponha à ameaça. Após a identificação dos papéis de cada agente na gestão de risco, o desafio é a efetiva ação de cada um deles, para finalmente caminhar para a consolidação de uma cultura de prevenção de risco no Maciço do Morro da Cruz, pois conviver com o risco é praticamente uma regra, contabilizar vítimas é opcional.

\section{REFERÊNCIAS}

ABNT. Norma NBR ISO 31000 (ago/2009): Gestão de Riscos. Rio de Janeiro:ABNT, 2009

AFONSO, S. Urbanização de encostas e ocupação do Morro da Cruz. São Paulo, 1992, 376p. Dissertação (Mestrado em Arquitetura) - Faculdade de Arquitetura e Urbanismo, Universidade de São Paulo CADHAB/SHSA (2008).

CEPREDENAC - Centro de Coordinación para la Prevención de los Desastres Naturales en América Central. La Gestión Local Del Riesgo nociones y precisiones en torno al concepto y la práctica. Guatemala, 2003.

EIRD - Estrategia Internacional Para La Reducción De Desastres - Naciones Unidas. Vivir con el Riesgo: informe mundial sobre iniciativas para La reducción de desastres. Secretaría Interinstitucional de la Estrategia Internacional para La Reducción de Desastres, Naciones Unidas (EIRD/ONU), 2004.

HOUAISS, A. Dicionário Houaiss de língua portuguesa. Rio de Janeiro, Objetiva, $1^{\circ}$ ed,2003.

IPUF - Instituto de Planejamento Urbano de Florianópolis. Perfil das áreas carentes. Florianópolis, 1993.

KOBIYAMA, M. .CHECCHIA, T.; SILVA, R.V.; SCHRODER, P.H.; GRANDO, A. REGINATTO, G.M.P. Papel da comunidade e da universidade no gerenciamento de desastres naturais. In: Anais...SIMPÓSIO BRASILEIRO DE DESASTRES NATURAIS. 2004, 834-846p.

NEGREDO, J. C. A Defesa Civil que não se conhece ou que não se vê. In: FRANK, B. SEVEGNANI, L. Desastre de 2008 no vale do Itajaí Água, gente e política. Blumenau: Agencia de Água do Vale do Itajaí, 2009. 
PMRR - PLANO MUNICIPAL DE REDUCAO DE RISCO DE FLORIANÓPOLIS -. Relatório do Plano Municipal de Redução de Risco. Florianópolis: UFSCCEPED/PMF. 2006.

PRIETO, J.P.S. El desafio de la Gestión de Riesgos como estrategia de intervención multisetorial y participativa al servicio del desarrollo. IN: Grupo Internacional Recursos del Sur - IRG. Tiempo para entregar el relevo: reducción del riesgo de desastre desde la perspectiva de la gestión ambiental, ordenamiento territorial, finanzas e inversión pública. Costa Rica, USAID, 2007.

RAIMUNDO, H. A. Aspectos Geotécnicos e Pluviométricos Associados a Instabilidade de Encostas em Florianópolis - SC. 1998. 325p. Dissertação (Mestrado em Engenharia Civil) - Curso de Pós-Graduação em Engenharia Civil, Universidade Federal de Santa Catarina, Florianópolis, 1998.

REGO NETO, C. B. Morro da Cruz - Florianópolis/SC: condicionantes geológico-geotécnicos ao uso do solo. Rio de Janeiro, 1988, 150p. Dissertação (Mestrado em Geologia) - Universidade Federal do Rio de Janeiro, Rio de Janeiro, 1988.

SAITO, S.M. Estudo analítico da suscetibilidade a escorregamentos e quedas de blocos no Maciço Central de Florianópolis-SC, Florianópolis, 2004, 132p. Dissertação (Mestrado em Geografia) - Departamento de Geociências, Universidade Federal de Santa Catarina, 2004.

TOMAZZOLI, E. R. ; PELLERIN, J. R G M . Geologia e Geomorfologia da Área de Influência do Maciço Central da Cidade de Florianópolis. In: IV SIMPÓSIO NACIONAL DE GEOMORFOLOGIA, 2002, São Luiz - MA. Anais, 2002. v. 1. p. 101102. 